\title{
Analysis of static structural of ocean FARMITS offshore cage due to environmental load
}

\author{
Yani Purnawanti ${ }^{1}$, Nur Syahroni ${ }^{1}$, and Yeyes Mulyadi ${ }^{1}$ \\ ${ }^{1}$ Ocean Engineering Department, Faculty of Marine Technology, Sepuluh Nopember Institute of \\ Technology, Indonesia
}

\begin{abstract}
Consumption of fish in Indonesia continuously increase from 2000 to 2014. Particularly fish farming in Java from 2006-2014 is quite high, so there need to be adequate facilities for fish farming. Responding to these challenges, we developed Offshore Cage Ocean FARMITS technology specifically designed For the southern waters of Java Island. This paper discusses the static structure strength analysis of deformation and maximum yield strength that occurs on the offshore cage structure of Ocean FARMITS. The frame structure made of hollow pipe made from HDPE will be placed at $4,41 \mathrm{~m}$ Wave Height, with a period of $19 \mathrm{~s}$. Numerical simulations are performed to obtain a motion response RAO and structural response due to random waves. This Structure is then analyzed under mooring conditions with the Catenary Mooring configuration. Rope stress that occur due to environmental loads will give tension stress to the structure, resulting in the offshore cage structure to occur maximum stress and deformation. The result of this research is to prove that the structure that is made by HDPE able to restrain the tension force of mooring line stress. This has been validated by the standard of Practical Aspects of Offshore Aquaculture System Design from Aquaculture America, so this structure can be said to be operating safely under Indonesian Irregular Wave.
\end{abstract}

\section{Introduction}

Consumption of fish in Indonesia continuously increase from 2000 to 2014. Particularly fish farming in Java from 2006-2014 is quite high, so there need to be adequate facilities for fish farming. Aquaculture technology began to develop since the 1970s, to date has grown rapidly in the food procurement sector with an increase of $32.4 \%$ in 2004 . The sea-cage industry has existed in Norway, Chile, China, Spain, Australia, Japan, Indonesia, Scotland, Ireland, Canada, Greece and Faroe Island with various species cultivation[1].

Ocean FARMITS is a new innovation developed by Marine Reearch Center LPPM ITS Surabaya. This design is very suitable for Indonesian waters. In addition to the maximum cage volume, fabrication can also be done easily. For a mooring design of Ocean FARMITS Offshore Cage using catenary mooring system as in Figure 1.

This mooring system allows the movement of the structure to be rather large but can decrease mooring line tension. The combined mooring system of several cages used rectangular array as is moored to buoy, then buoy moored to anchor on the seabed. Such mooring systems are more effective than single mooring systems[2]. 
The study of parameter sensitivity on mooring line floating cage states that mooring loads are not sensitive to wave load variations for floating Cage structures with elastic floater[3]. But the effect of wave height when in irregular condition is more than in regular conditions [4]. The speed of ocean currents is also very influential on the floating cage stability. Further research is about the single dynamic behavior of point mooring semisubmersible fish cage with variations of current velocity[5].. The numerical analysis of mooring rope stresses and deformation of floating fish Cage structures was performed by Huang, et.al (2016). Based on the above reference we would like to do research on Offshore Cage Ocean FARMITS [6].

This paper aims to determine the effect of environmental condition on motion response and structural strength. Motion response due to environmental load causes tension on the mooring rope. The Strength of the structure can be seen through the magnitude of stress and deformation that occur due to the tension force of the mooring rope on the structure.

\section{Description of Models}

\subsection{Detail Structure Offshore Cage Ocean FARMITS}

Ocean FARMITS is a new innovation developed by Marine Research Center LPPM ITS Surabaya. This design is very suitable for Indonesian waters. In addition to the maximum cage volume, fabrication can also be done easily. Structural model of Ocean FARMITS Offshore cage is used to strength analysis with FEM simulation. This design uses HDPE PE 100 for material with yield strength $26 \mathrm{Mpa}$ and tensile strength 31,7 Mpa [7]. Mooring lines on Offshore Cage Ocean FARMITS use nylon rope properties from a field handbook Aquaculture Operation in Floating HDPE cage 2015.

Offshore Cage Ocean FARMITS is designed for $6100 \mathrm{~m} 3$ cage volume. For the initial design use the dimension $\mathrm{D}=28 \mathrm{~m}$ and $\mathrm{H}=10 \mathrm{~m}$ as seen in Figure 1. Detailed size of the Offshore Cage Ocean FARMITS structure is shown in Table 1. The data in Table 1 refers to the reference "Aquaculture for Floating HDPE Cage"[8]. Details of parts of the structure in the table can be seen in the Figure 1.

Table 1. The Dimension of Offshore Cage Ocean FARMITS

\begin{tabular}{|l|l|l|l|c|}
\hline Part & OD & Thickness & Quantity & Length \\
\hline Pontoon Ring Outside & $0,40 \mathrm{~m}$ & $0,02 \mathrm{~m}$ & 1 & $62,2 \mathrm{~m}$ \\
\hline Sling & $0,10 \mathrm{~m}$ & $0,01 \mathrm{~m}$ & 8 & $19,8 \mathrm{~m}$ \\
\hline Horizontal Pontoon & $0,20 \mathrm{~m}$ & $0,01 \mathrm{~m}$ & 8 & $4,95 \mathrm{~m}$ \\
\hline Pontoon Ring Inside & $0,28 \mathrm{~m}$ & $0,02 \mathrm{~m}$ & 1 & $31,1 \mathrm{~m}$ \\
\hline Upper pontoon ring & $0,25 \mathrm{~m}$ & $0,01 \mathrm{~m}$ & 1 & $15,5 \mathrm{~m}$ \\
\hline Umbrella Frame & $0,20 \mathrm{~m}$ & $0,01 \mathrm{~m}$ & 6 & $6,0 \mathrm{~m}$ \\
\hline
\end{tabular}

The detailed structure can be seen in figure 1. In Figure 1 it is seen that the structure of Ocean FARMITS has 3 main parts, there are the deck, upper deck, and underwater structure. At the underwater there is a damper to reduce the movement of the structure. There is also a sinker tube that serves as a ballast system. On the deck, there are several brackets as reinforcement. At the top of the deck, there is an umbrella frame to easily fish harvesting process. 


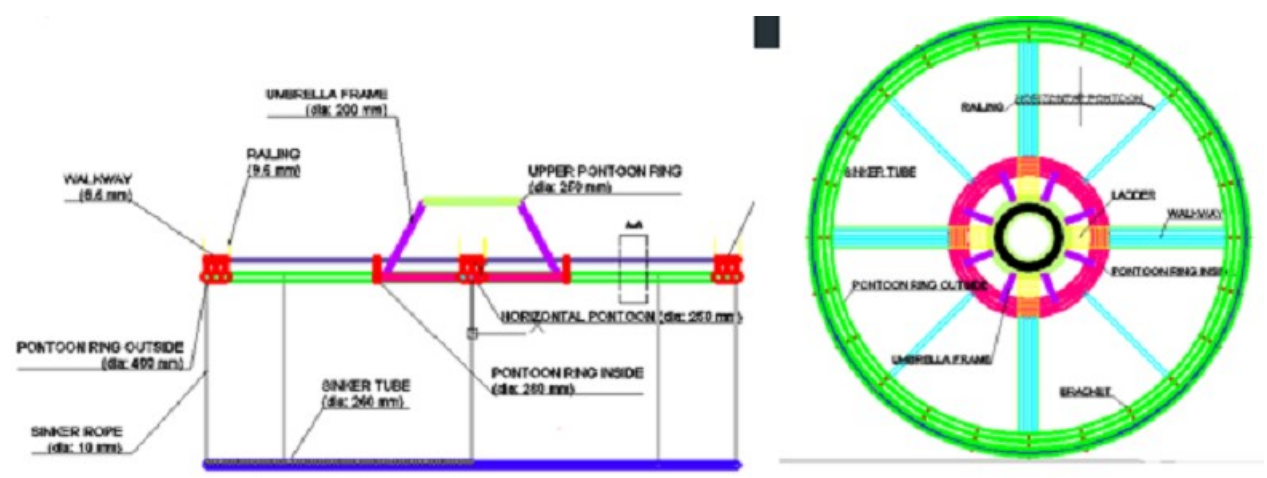

Fig. 1. Detail Structure Offshore Cage Ocean FARMITS

Environmental load (wind, wave, current) on the Offshore Cage Ocean FARMITS structure accumulates in the tension mooring line load. The size of the tension on the mooring line is the result of structural displacement due to the hydrodynamic load (surge, sway, heave, roll, pitch, yaw). In this structure the hydrodynamic load is analyzed under hurricane conditions, recording 100 year of wave, currents and wind data. For more details, the scheme in figure $\mathrm{xx}$ is a condition when the structure is exposed to the maximum tension load.

\subsection{Hydrodynamics Model}

Hydrodynamic modeling is performed to obtain the motion response of Ocean FARMITS structure on regular and irregular waves. Motions of structure on a regular wave can be shown through RAO (Response Amplitude Operator). RAO is obtained from the frequency domain numerical simulation. [9]

The floating cage under consideration consists of six degree of freedom modes, assuming that the oscillation movements are linear and harmonic, the coupling differential equation $\mathrm{s}$ can be written as follows equation 1 :

$$
\sum_{n=1}^{6}\left[\left(M_{j k}+A_{j k}\right) \xi_{k}+B_{j k} \xi_{k}+C_{j k} \xi_{k}\right]=F_{j} e^{i w t}, j=1
$$

where Mjk is the components of structure's mass matrix, Ajk, Bjk are matrix of added mass and damping coefficient, $\mathrm{Cjk}$ is restoring force coefficients, and $\mathrm{Fj}$ is amplitude of excitation force in complex quantities. F1, F2, dan F3 is the amplitude of excitation forces which result in surge, sway, and heave, while F4, F5, and F6 are the amplitude of excitation moments for roll, pitch, and yaw.

\subsection{Structure Response due to Environmental Load}

The structure response can be known through the multiplication of RAO squares with the wave spectrum. The response spectrum can be defined as the distribution of wave structure energy. It is formulated on equation 2 :

$$
S_{R}=[R A O(\omega)]^{2} S(\omega)
$$

where $S_{R}$ spektrum respons, S(w) spektrum gelombang RAO (w) transfer function and w frekuensi gelombang. The wave spectrum equation used in this analysis is the JONSWAP spectrum equation because the parameters are included according to the characteristics of the closed seas or islands [10]. The JONSWAP spectrum equation is as follows equation 3: 


$$
S(\omega)=\alpha g^{2} \omega^{-5} E X P\left[-1,25\left(\frac{\omega}{\omega_{0}}\right)^{-4}\right] \gamma^{E X P\left[\frac{-\left(\omega-\omega_{0}\right)^{2}}{2 \tau^{2} \omega_{0}^{2}}\right]}
$$

where

$$
\begin{array}{ll}
\alpha & : 0,076(\mathrm{X} 0)-0.22 \\
\mathrm{X} 0 & : \mathrm{gX} / \mathrm{Uw} 2 \\
\mathrm{X} & : \text { fetch length } \\
\mathrm{Uw} & : \text { wind speed } \\
\alpha & : 0.0081 \text { if } \mathrm{X} \text { not defined } \\
\Upsilon & : \text { peak parameter, can be defined by equation } 4: \\
\quad \gamma=\operatorname{EXP}\left[3,4843\left(1-0,1975\left(0,036-0,0056 \frac{T_{P}}{\sqrt{H_{S}}}\right) \frac{T_{P}{ }^{4}}{H_{S}{ }^{2}}\right)\right]
\end{array}
$$

where

Tp : peak period of spectra

Hs : Significant wave height

$\tau \quad$ : shape parameter (for $\omega \leq \omega 0=0,07$ and $\omega \geq \omega 0=0,09$ )

$\omega 0$

$$
:^{2 n}\left(\frac{g}{v_{\omega}}\right)(x u)-0,33
$$

Numerical simulations are performed with free floating and moored conditions. It is as depicted in the Figure 2.

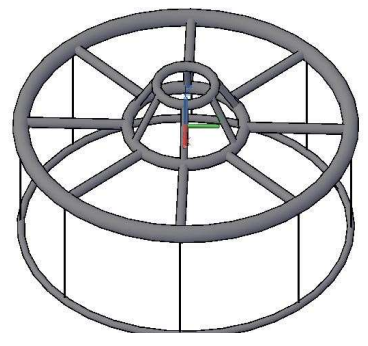

(a)

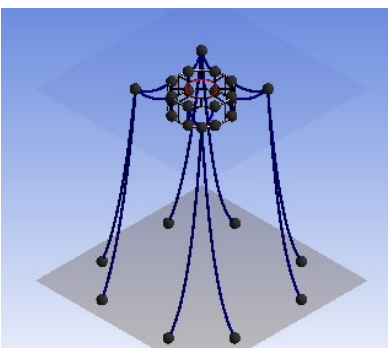

(b)

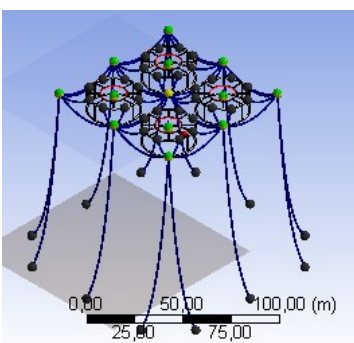

(c)

Fig. 2. (a) Surface Model (b) single moored condition (c) combined mooring condition

Figure 2.a is a surface model of Offshore Cage Ocean FARMITS for hydrodynamics diffraction analysis on free floating conditions. Figure 2.b is a surface model in moored condition, whereas in Figure 2.c is a combination mooring condition. This mooring configuration is more effective in its operation.

\subsection{Finite Element Model}

Finite element model is used in the calculation of mooring tension and structure stress of Ocean FARMITS. On the mooring line, each rope is divided into segments. Where there is a node on each end of the segment. In each segment rope is modeled its axial properties only. The properties of the mooring rope are mass, weight, buoyancy, cross section area, etc. The load is applied to nodes in the form of force and moment (weight, buoyancy, hydrodynamic drag, tension, etc.). Bending properties are facilitated by springs in segments[6]. The Equation 5 is for each segment nodal:

$$
\mathrm{M}(\mathrm{p} . \mathrm{a})+\mathrm{C}(\mathrm{p}, \mathrm{v})+\mathrm{K}(\mathrm{p})=\mathrm{F}(\mathrm{p} . \mathrm{v}, \mathrm{t})
$$


where $\mathrm{M}(\mathrm{p}, \mathrm{a})$ is the system inertia load, $\mathrm{C}(\mathrm{p}, \mathrm{v})$ is the system damping load, $\mathrm{K}(\mathrm{p})$ is the system stiffness load, $F(p, v, t)$ is the external load, $t$ is the simulation time, $p, v$ and a are the position, velocity, and acceleration.

FEM modeling on structures is required to obtain maximum stress and maximum deformation. In the picture $\mathrm{xx}$ meshing has been done on the structure to divide into several elements and nodal. In this case the element used is a solid element with the boundary condition shown in the Figure $3 \mathrm{~b}$. In the Figure $3 \mathrm{c}$ section $\mathrm{A}$ to the ends are given fixed support while at the ends of element B is given a roll. C, D, E, F are the force inputs given from the maximum tension mooring line results. FEM modeling is only half done just to review the section affected by the maximum force.

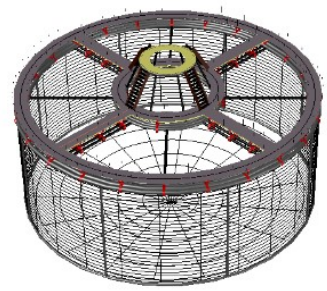

(a)

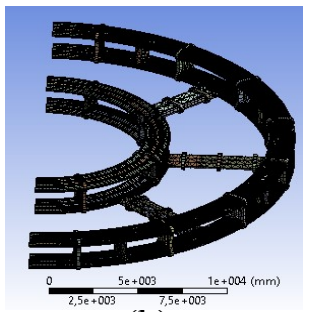

(b)

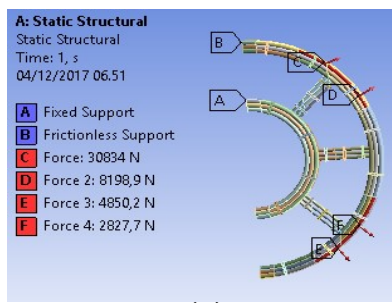

(c)

Fig. 3. (a) detail structure model (b) structure meshed (c) boundary condition

\section{Environmental Data}

The environmental data in Table 2 is the result from the processing of satellite images on the southern waters of Java Island precisely at the coordinates of Longitude 108.02 Latitude 7.88 with water depth $102 \mathrm{~m}$. Environmental data such as wave height, wave period, and wind speed, are obtained from ECMWF satellite extraction (European Center for MediumRange Weather Forecasts). Observations are made between 06:00 and 00:00. Depth data is obtained from GEBCO (General Bathymetric Chart of the Oceans). As for the current velocity obtained from OSCAR (Ocean Surface Current Analyses Real-time).

Table 2. Environmental Load on the southern waters of Java Island

\begin{tabular}{|l|l|l|l|}
\hline \multicolumn{2}{|l|}{ Parameter } & Unit & Storm Condition \\
\hline Waves & Height (Hs) & $\mathrm{m}$ & 4,41 \\
\hline & Period (Tp) & $\mathrm{s}$ & 11,61 \\
\hline Wind & Velocity (Vw) & $\mathrm{m} / \mathrm{s}$ & 4,5 \\
\hline Current & Velocity (Vc) & $\mathrm{m} / \mathrm{s}$ & 0,3 \\
\hline
\end{tabular}

Environmental loads in Table 2 are illustrated by JONSWAP spectrum theory become as in figure 4 . In the Figure 4 the wave frequency is located at a frequency of $0.6 \mathrm{rad} / \mathrm{s}$. 


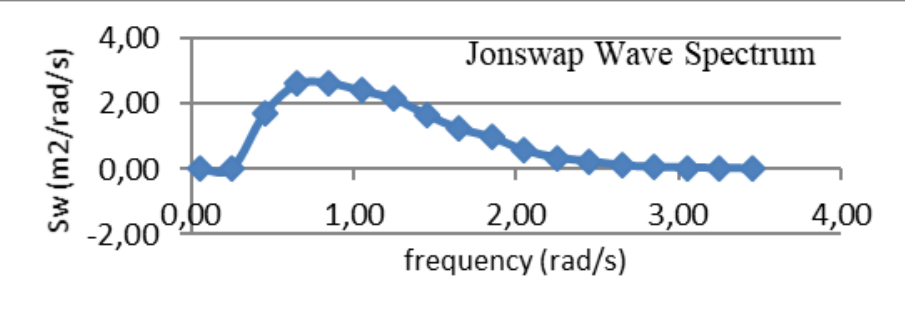

Fig. 4. Jonswap Wave Spectrum

\section{Result and Discussion}

\subsection{Motion}

Offshore Cage Ocean FARMITS oscillates in translational and rotational. Motions in this structure can be seen through RAO. The graph of RAO in Figure 5 shows the magnitude of movement of structures in the regular wave at each $\mathrm{m}$ of wave height. RAO is a transfer function for structural response due to random wave. The image is one of the largest RAO forms of rotational oscillation roll motion in free floating and moored conditions. At the time of free floating Figure 5(a) maximum roll reaches $7.6 \mathrm{deg} / \mathrm{m}$ at a frequency of $0.7 \mathrm{rad}$ / s while at moored roll the maximum occurs at a frequency of $1 \mathrm{rad} / \mathrm{s}$ of $3.9 \mathrm{deg} / \mathrm{s}$. This indicates that mooring condition can change the natural frequency of the structure shifts away from the wave natural frequency, due to the weight and stiffness of the mooring line. This is resulted in the magnitude of tension on the mooring line.

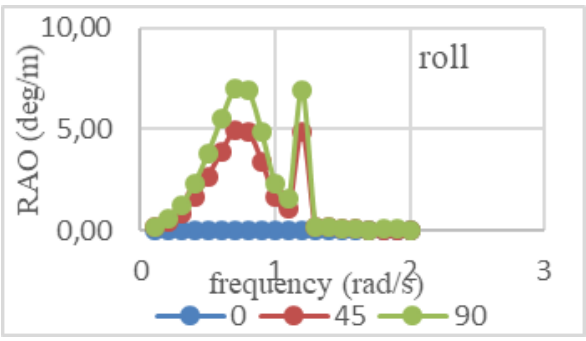

(a)

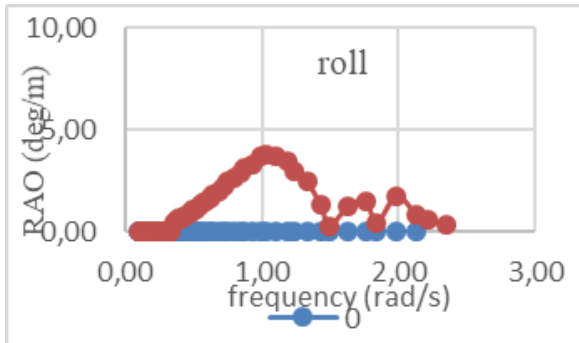

(b)

Fig. 5. (a) Roll Motion Free Floating (b) Roll Motion Moored

\subsection{Tension}

Tension on the mooring line occurs because the lines hold the structural motions due to environmental load. The numerical simulation to get maximum tension is done with time domain analysis. This simulation can accommodate these non-linear factors, so the motion equation of Newton's second law is solved in time function or better known as time domain analysis. The equation is described as Equation 6:

$$
\begin{aligned}
& {[m+A(\omega)] \ddot{x}+C(\omega) \dot{x}+D_{1} \dot{x}+D_{2} f(\dot{x})+K x=q_{W n}+} \\
& q_{W A}^{1}+q_{W A}^{2}+q_{e v}+q_{x e t}
\end{aligned}
$$

Where $q_{W I}$ wind drag force, $q_{W A}^{1}$ first order wave load, $q_{W A}^{2}$ second order wave load, $q_{C U}$ current load, $q_{x e t}$ other external load. 


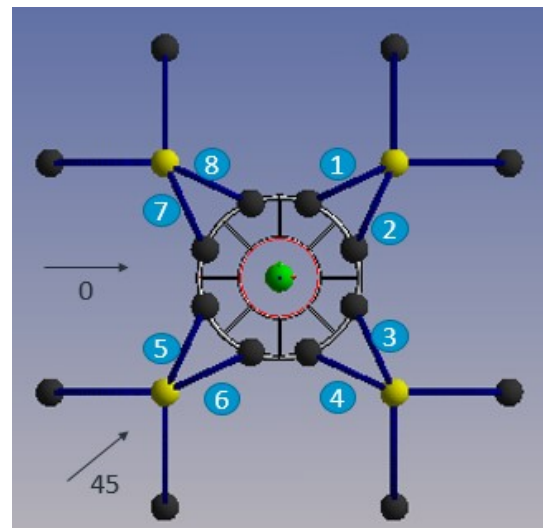

Fig. 6. Load Condition on the Mooring Line

Table 3. Maximum Tension on the Mooring Line

\begin{tabular}{|c|c|c|c|c|c|c|c|c|c|}
\hline Dir. & \multicolumn{7}{|c|}{ Maximum Tension (N) } & Time \\
\hline & Line 1 & Line 2 & $\begin{array}{c}\text { Line } \\
3\end{array}$ & $\begin{array}{c}\text { Line } \\
4\end{array}$ & Line 5 & Line 6 & Line 7 & Line 8 & \\
\hline 0 & 9903 & 9783 & 8910 & 9031 & 38610 & 15100 & 38751 & 15231 & $26 \mathrm{~s}$ \\
\hline 45 & 13225 & 13220 & 3536 & 9863 & 51403 & 51370 & 9764 & 3537 & $62 \mathrm{~s}$ \\
\hline
\end{tabular}

Figure 6 is a loading condition on the mooring line. The direction of the environmental load comes from the direction of 0 degrees and 45 degress, because from this direction it produces the dominant response. Maximum tension is presented in the Table 3 occurs when the environmental load direction comes from 45 degrees. Maximum tension occurs on line 5 and line 6.This happens because the lines are loaded directly. This mooring tensions analysis was done by time domain simulation on storm condition.

\subsection{Stress and Deformation}

The tension that occurs on the mooring line leads to tension on the Offshore Cage Ocean FARMITS structure. Like the scheme in Figure 6 and Figure 3c, the mooring line is attached to the pontoon structure of Offshore cage Ocean FARMITS. So if the tension on a large mooring line, then the voltage that occurs in the structure is also large. Strength analysis on this structure is done to check the von misses stress that occurs in the structure. Von Misses Stress is derived from the Equation 7:

$$
\begin{aligned}
& \sigma_{\theta Q}= \\
& \frac{1}{2} \sqrt{\left(\sigma_{x}-\sigma_{y}\right)^{2}+\left(\sigma_{y}-\sigma_{z}\right)^{2}+\left(\sigma_{z}-\sigma_{x}\right)^{2}+\sigma\left(\tau_{x y}^{2}+\tau_{y z}^{2}+\tau_{z x}^{2}\right)}
\end{aligned}
$$

where

$\sigma_{e q}$ von mises stress, $\sigma_{x}$ normal stress x axis, $\sigma_{y}$ normal stress y axis, $\sigma_{z}$ normal stress z axis, $\tau_{x y}$ shear stress xy plane, $\tau_{y z}$ shear stress yz plane, $\tau_{z x}$ shear stress zx plane.

Maximum stress is obtained from the Finite Element Method, which before generating the stress of the model is done meshing to divide the segment and nodal. The meshing size is $0.5 \mathrm{~mm}$. This is the most optimum meshing size after meshing sensitivity analysis as in Figure 7b. In the Figure 7a is shown one part of the structure that has been done meshing. Meshing is done by dividing critical and non critical areas. Critical area is an area that is exposed to direct force so that required a more dense meshing. For the critical meshing area 
use hexahedral meshing with optimum size $0.5 \mathrm{~mm}$ on each element. While for noncritical areas use triangular meshing with a larger size lead to decrease very long time for the simulation.

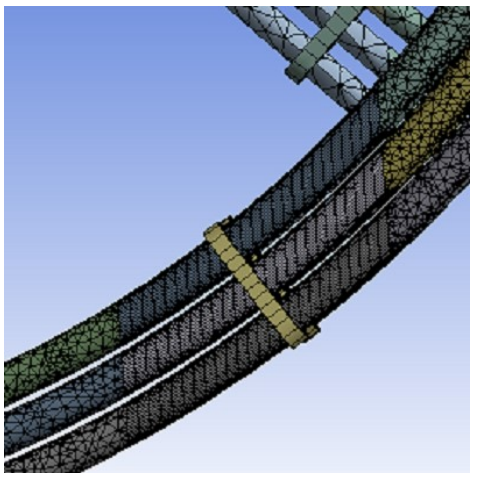

(a)

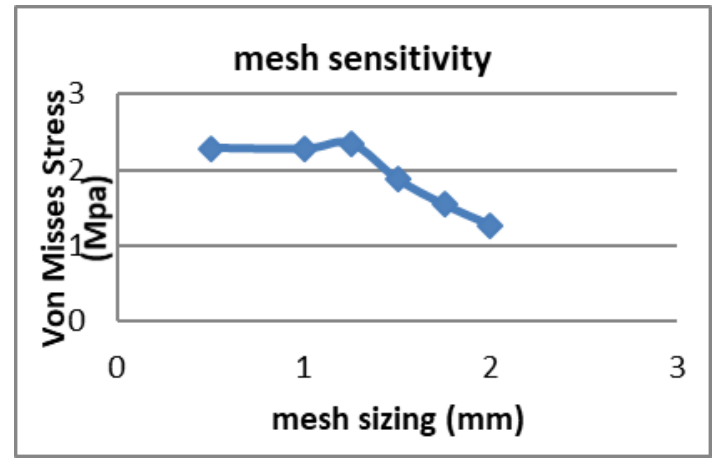

(b)

Fig. 8. (a) Structural mesh (b) sensitivity analysis

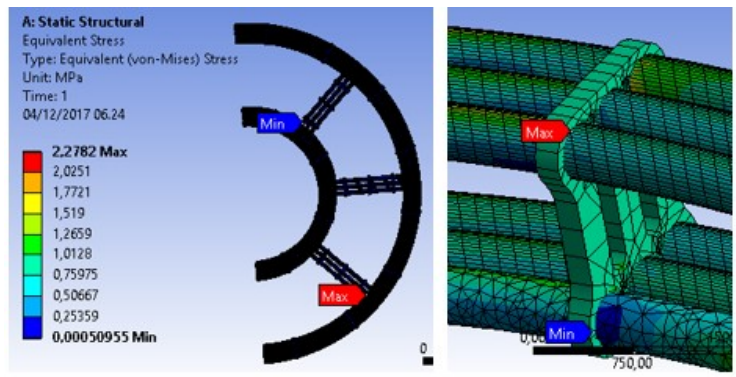

Fig. 9. Maximum Von Misses Stress

Figure 8 is the maximum stress result on the Offshore Cage Ocean FARMITS structure. Maximum tension occurs in the upper bracket area as it retains the deflection from the pontoon where the rope is tied. The mooring scenario is done on the upper pontoon, so the pontoon is deflected. Maximum von misses stress in this structure 2,28 Mpa. This value is less than $26 \mathrm{Mpa}$ (Yield Strength HDPE) so this structure is safe to operate in this location even in storm conditions.
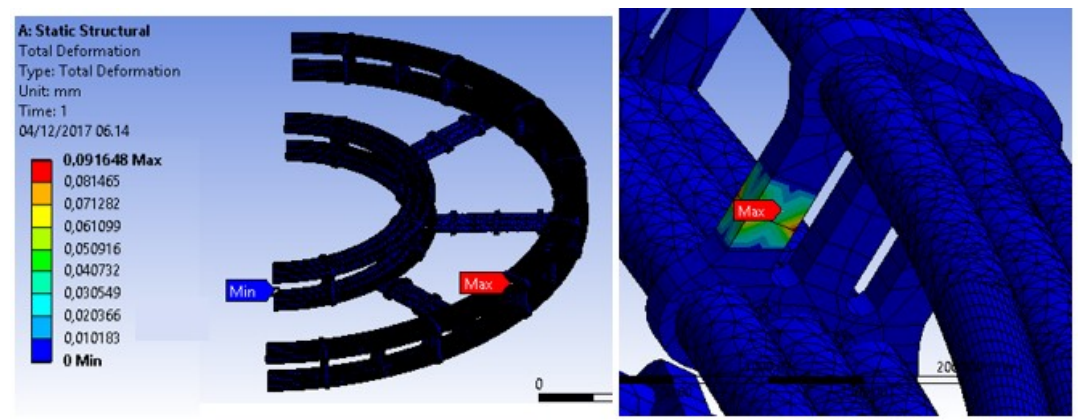

Fig. 10. Total Deformation

Figure 9 is the maximum deformation that occurs in the middle of the bracket. According to previous research about HDPE collar cage[6], the deformation for OD $=0.4 \mathrm{~m}$ and 
thickness $20 \mathrm{~mm}$, the strain should be $0.4 \%-0.5 \%$. So, for this case the maximum deformation should be less than $0.31 \mathrm{~mm}$.

\section{Conclusion}

Environmental conditions greatly affect the strength of the structure. This is related to the motion of the structure generated, then the tension force on the mooring line to withstand movement, attributed to the upper pontoon of the structure. This gives the result that the effect of Environmental Load on Southern Waters of Java Island is Maximum tension is obtained when the structure is affected by $45 \mathrm{kN}$. Maximum Stress is located on the bracket of 2.28 MPa. This value is still far from the Yield Stress HDPE PE 100, so the structure is still safe in storm conditions. Maximum deformation is $1 \mathrm{~mm}$ located on the middle of bracket.

\section{References}

1. FAO. The state of world fisheries and Aquaculture. Rome: Food and Agriculture Organization of the United Nations; (2006) p. 162.

2. Goudey, C.A. Practical Aspects of Offshore Aquaculture System Design. In Presentation at the World Aquaculture Society: Aquaculture America 2009. Seattle. America; (2009).

3. Kristiansen, T., Faltinsen,O.M. Experimental and numerical study of an Aquaculture net Cage. Elsevier, (2014) p.1-26.

4. Shainee, M.et.al., Investigation of Self-Semisubmersible SPM Cages System in Random Waves. Elsevier (2013).

5. Decew, et.al. Modeling of dynamic behavior of a tunggal-point moored submersible. ELsevier, (2010) p.38-45.

6. Huang, X. et.al. Numerical Simulation Of Deformations And Forces Of A Floating Fish Cage Collar In Waves. Elsevier, (2016) p.111-119.

7. Vielma,J.,Kankainen,M. Offshore Fish farming Technology in Baltic Sea Production Conditions. Part-financed by the European Union Baltic Sea Region (2013).

8. Cardia, F., Lovatelli, A., Aquaculture operations in floating HDPE Cages. Rome : FAO and Ministry of Agriculture of the Kingdom of Saudi Arabia (2015).

9. Bhattacharyya. R., Dynamics of Marine Vehicles, New York: John Wiley \& Sons Inc.(1978).

10. Chakrabarti, S.K., Hydrodynamics of Offshore Structures, USA: Computational (1987). 